\title{
PRODUÇÃO DE MATÉRIA SECA E COMPOSIÇÃO BROMATOLÓGICA DE GENÓTIPOS DE CAPIM-ELEFANTE ANÃO1
}

\author{
DRY MATTER PRODUCTION AND CHEMICAL COMPOSITION OF DWARF \\ ELEPHANTGRASS GENOTYPES
}

\author{
Araújo, S.A.C. ${ }^{2 *}$, Vasquez, H.M. ${ }^{2}$, Silva, J.F.C. ${ }^{2}$, Lima, E.S. ${ }^{2}$, Lista, F.N. ${ }^{2}$, Deminicis, B.B. ${ }^{3}$ e \\ Campos, P.R.S.S. ${ }^{2}$
}

${ }^{2}$ Laboratório de Zootecnia e Nutrição Animal. Centro de Ciências e Tecnologias Agropecuárias da UENF. Av. Alberto Lamego, 2000. Horto. CEP 28015-620. Campos dos Goytacazes, RJ. Brasil. *araujosac@yahoo.com.br

${ }^{3}$ Laboratório de Fitotecnia. CCTA/UENF. Campos dos Goytacazes, RJ. Brasil.

\section{PalaVRas ChaVE ADICIONAIS}

Avaliação de forrageiras. Seleção de forrageiras. Produtividade.

\section{RESUMO}

Foi realizado um experimento para avaliar a taxa de acúmulo de matéria seca (TAMS) e os teores de proteína bruta (PB), fibra em detergente neutro (FDN) e lignina em ácido sulfúrico (LAS) de genótipos de capim-elefante anão submetidos a diferentes intervalos de corte. O delineamento experimental foi o de blocos casualizados com três repetições em esquema de parcelas subdivididas, onde os genótipos foram alocados nas parcelas e os intervalos de corte nas subparcelas. Foram avaliados cinco genótipos de capimelefante anão (CNPGL 00-1-3, CNPGL 94-34-3, CNPGL 92-198-7, CNPGL 92-117-3 e CNPGL 00$1-5)$ e a cv. Mott em seis intervalos de corte (14, $28,42,56,70$ e 84 dias). O genótipo CNPGL 00-13 , considerado de porte intermediário, apresentou maior TAMS, entretanto, entre os demais genótipos de porte baixo, destacaram-se os genótipos CNPGL 92-198-7, Mott, CNPGL 94-34-3 e CNPGL 92-177-3. Quanto ao teor de PB, o genótipo CNPGL 00-1-3 e CNPGL 00-1-5 apresentaram comportamento linear e os demais genótipos apresentaram comportamento quadrático. O teor de FDN apresentou variação significativa em função dos

${ }^{1}$ Parte da dissertação de doutorado do primeiro autor, desenvolvida pelo Programa de Pós-Graduação em Ciência Animal da Universidade Estadual do Norte Fluminense Darcy Ribeiro-UENF.

Recibido: 19-11-08. Aceptado: 9-6-09.

\section{AdDitionAl KEYWORDS}

Evaluation of forage. Selection of forage. Productivity.

intervalos de corte apenas para os genótipos CNPGL 00-1-3 e CNPGL 92-198-7. Houve interação entre genótipos e intervalos de corte para os valores de LAS somente para os genótipos CNPGL 00-1-3, CNPGL 92-198-7 e CNPGL 92-117-3. Os genótipos CNPGL 92-198-7 e CNPGL 94-34-3 foram selecionados para a fase de avaliação em sistema de pastejo.

\section{SUMMARY}

The experiment was carried out to evaluate the dry mater accumulation rate (TAMS) and levels of crude protein (PB), neutral detergent fiber (FDN) and sulfuric acid lignin (LAS) in dwarf elephantgrass genotypes submitted to different cutting intervals. The experimental design was a randomized block with three replicates in a splitplot, where genotypes were allocated plots and subplots in the cutting intervals. Were evalued five genotypes of dwarf elephantgrass (CNPGL 00-13, CNPGL 94-34-3, CNPGL 92-198-7, CNPGL 92117-3, CNPGL 00-1-5) and cv. Mott in six cutting intervals $(14,28,42,56,70$ and 84 days). The genotype CNPGL 00-1-3 showed higher TAMS, however, among other dwarf genotypes, those who stood out were the genotypes CNPGL 92198-7, Mott, CNPGL 94-34-3 and CNPGL 92-1173. As for protein level, the CNPGL 00-1-3 and 
CNPGL 00-1-5 genotype showed linear behavior and the other genotypes showed quadratic behavior. The level of FDN showed significant variation depending on the cutting intervals only for the genotypes CNPGL 00-1-3 and CNPGL 92198-7. There was an interaction among genotypes and cutting intervals for the values of LAS only for the CNPGL 00-1-3, CNPGL 92-198-7 and CNPGL 92-117-3. Genotypes CNPGL 92-198-7 and CNPGL 94-34-3 were selected, together with the Mott genotype for the evaluation phase under grazing.

\section{INTRODUÇÃO}

A espécie Pennisetum purpureum Schum. apresenta genótipos com grande variabilidade genética, diferenciando-se por características morfológicas, reprodutivas, agronômicas e bioquímicas. Dentre os diferentes genótipos que compõe o germoplasma de capim-elefante, os de porte baixo (anão) tem despertado elevado interesse nos sistemas de pastejo. O capim-elefante anão foi primeiramente descoberto nos anos de 1940, e a cv. Mott foi selecionada em 1977, de uma progênie auto-fecundada da cultivar Merkeron, na Geórgia (EUA). A cv. Mott é a representante mais importante do grupo, podendo atingir uma altura máxima de $1,8 \mathrm{~m}$, forma touceira densa com alta relação folha/colmo, refletindo em elevado valor nutritivo.

Segundo Almeida et al. (2000), ela foi introduzida no Brasil a partir da década de 80 , mas ainda há poucos estudos sobre esta forrageira no país. Mott (1984) relatou que o capim-elefante anão cv. Mott tem capacidade de produção sob pastejo de 1,0 $\mathrm{kg}$ de ganho médio diário.

Segundo Veiga (1990), o sucesso dessa gramínea deve-se basear na manutenção do maior número possível de pontos de rebrota, por onde se dará o acúmulo de forragem otimizando a qualidade e mantendo a rebrota nos limites de alcance dos animais e em densidade adequada, com garantia de que o manejo não comprometa a persistência da pastagem. A adoção conjunta de tecnologias tem possibilitado atender a essas premissas e, assim, promover o uso eficiente da pastagem de capim-elefante anão, garantindo aumento em produtividade e redução nos custos de produção (Lopes et al., 2003).

Dentre essas tecnologias, destaca-se a definição do intervalo de corte ideal para cada forrageira e sistema de produção, permitindo associar a produção satisfatória à boa qualidade da forragem (Santana et al., 1994). De fato, a pronta recuperação do dossel após pastejo guarda alta correlação com a produção de forragem que depende do período de descanso, cuja duração deve observar a restauração das reservas orgânicas e área foliar residual, a interceptação luminosa pelo dossel, a perda por senescência e respiração, e o número de folhas vivas por perfilho (Cândido et al., 2005).

O presente estudo teve por objetivo avaliar as características quantitativas e qualitativas de genótipos de capim-elefante anão desenvolvidos pela EMBRAPA Gado de Leite sob intervalos de corte variáveis promovendo a seleção dos mais promissores para a fase de pastejo.

\section{MATERIALEMÉTODOS}

$O$ experimento foi conduzido nas instalações do Setor de Forragicultura e Nutrição de Ruminantes do Laboratório de Zootecnia e Nutrição Animal, pertencentes ao Centro de Ciências e Tecnologias Agropecuárias da Universidade Estadual do Norte Fluminense Darcy Ribeiro (UENF) no município de Campos dos Goytacazes, localizado a $21^{\circ} 44^{\prime} 47^{\prime \prime}$ de latitude sul, $41^{\circ} 18^{\prime} 24^{\prime \prime}$ de longitude oeste e $11 \mathrm{~m}$ do nível do mar da região fisiográfica do norte do estado do Rio de Janeiro/Brasil.

O clima da região segundo a classificação de Köppen (1948) é do tipo Aw, tropical quente e úmido com período seco no inverno e chuvoso no verão. Os valores médios mensais da temperatura, umidade relativa do ar e precipitação pluviométrica do período 
experimental são apresentados na tabela $\mathbf{I}$.

O solo da área experimental é classificado como um Latossolo Amarelo Distrófico Típico (EMBRAPA, 2006), apresentando a seguinte composição química: $\mathrm{pH}=5,5 ; \mathrm{P}=4$ e $\mathrm{K}=36 \mathrm{mg} \cdot \mathrm{dm}^{-3}$ respectivamente, $\mathrm{Ca}+\mathrm{Mg}=$ 2,2 e $\mathrm{Al}=0,2 \mathrm{cmol} \cdot \mathrm{dm}^{-3}$. Foi realizada a calagem do solo utilizando-se 1,0 t.ha ${ }^{-1}$ de calcário dolomítico PRNT 96\%, com o objetivo de elevar a saturação por bases a $60 \%$.

Os genótipos de capim-elefante anão foram obtidos pelo programa de melhoramento genético de capim-elefante da EMBRAPA Gado de Leite: CNPGL 00-1-3, CNPGL 94-34-3, CNPGL 92-198-7, CNPGL 92-117-3, CNPGL 00-1-5 e a cv. Mott. Os parâmetros quantitativos e qualitativos foram avaliados em intervalos de corte de $14,28,42,56,70$ e 84 dias, em esquema de parcelas subdivididas, onde os genótipos foram alocados nas parcelas e os intervalos de corte nas subparcelas.

O plantio foi realizado através de mudas, sendo que cada subparcela foi composta por quatro fileiras de três metros de comprimento com espaçamento entre si de $1 \mathrm{~m}$. Para efeito da unidade de amostragem foi desprezado um metro de cada extremidade e uma fileira em cada lateral. A área experimental correspondeu a aproximadamente $1600 \mathrm{~m}^{2}$, na qual cada parcela foi constituída por um genótipo, com uma área de $72 \mathrm{~m}^{2}$, enquanto a subparcela correspondeu aos intervalos de corte com $12 \mathrm{~m}^{2}$.

O corte de uniformização foi feito a $30 \mathrm{~cm}$ de solo e 60 dias após o plantio. A adubação foi realizada de acordo com os resultados de análise do solo e também em concordância com as recomendações da EMBRAPA Gado de Leite: aplicação de $100 \mathrm{~kg} \cdot \mathrm{ha}^{-1}$ de $\mathrm{P}_{2} \mathrm{O}_{5}$ (superfosfato simples) no momento do plantio. A adubação de cobertura com nitrogênio e potássio foi realizada em três aplicações de mesma quantidade nos meses de janeiro, março e dezembro de 2005, perfazendo um total de $200 \mathrm{~kg} \cdot \mathrm{ha}^{-1}$ de N na forma de uréia e $200 \mathrm{~kg} \cdot \mathrm{ha}^{-1} \mathrm{de}_{2} \mathrm{O}$ na forma de cloreto de potássio. $\mathrm{O}$ experimento foi desenvolvido durante o período das chuvas (seis meses) do ano de 2005.

As características morfológicas de crescimento foram avaliadas para a caracterização dos genótipos utilizando-se o maior intervalo de corte ( 84 dias). Quanto à altura da planta, as medidas foram obtidas a partir do nível do solo à altura de curvatura das folhas superiores, com o auxílio de uma régua graduada a uma distância de aproximadamente $5 \mathrm{~m}$ do observador. Para a avaliação do diâmetro do colmo e do número de folhas foram selecionados cinco perfilhos principais por unidade de amostragem. $\mathrm{O}$ diâmetro do colmo foi determinado no segundo entre-nó dos perfilhos pré-sele-

Tabela I. Climatologia durante o periodo experimental. (Climatology during the experimental period).

\begin{tabular}{|c|c|c|c|c|c|c|c|}
\hline \multirow[t]{2}{*}{ Mês/Ano } & \multirow{2}{*}{$\begin{array}{l}\text { Precipitação } \\
(\mathrm{mm})\end{array}$} & \multicolumn{3}{|c|}{ Temperatura $\left({ }^{\circ} \mathrm{C}\right)$} & \multicolumn{3}{|c|}{ Umidade relativa do ar (\%) } \\
\hline & & média & máxima & minima & média & máxima & média \\
\hline Jan./2005 & 224,0 & 25,2 & 30,4 & 21,8 & 81,9 & 99,1 & 54,2 \\
\hline Fev./2005 & 58,8 & 25,2 & 31,3 & 21,1 & 78,5 & 99,7 & 45,9 \\
\hline Mar./2005 & 159,7 & 25,4 & 31,2 & 21,8 & 82,6 & 99,6 & 51,9 \\
\hline Out./2005 & 38,6 & 24,0 & 29,9 & 20,0 & 78,0 & 98,9 & 47,0 \\
\hline Nov./2005 & 219,1 & 22,7 & 27,2 & 19,6 & 83,8 & 99,2 & 57,8 \\
\hline Dez./2005 & 250,8 & 23,8 & 28,6 & 20,1 & 80,3 & 99,6 & 54,8 \\
\hline
\end{tabular}

Fonte: Estação Meteorológica PESAGRO-2005, Campos dos Goytacazes/RJ. 
cionados. O número de folhas por perfilho foi determinado após a separação do caule e lâmina foliar verde para a determinação da relação folha/colmo. O número de perfilhos foi determinado pela contagem na unidade de amostragem.

A taxa de acúmulo de matéria seca (TAMS) foi obtida pelo somatório das colheitas, como segue: para os intervalos de 14 dias (12 colheitas), 28 dias (6 colheitas), 42 dias ( 4 colheitas), 56 dias ( 3 colheitas), 70 dias ( 2 colheitas) e 84 dias ( 2 colheitas). O teor de matéria seca foi determinado por meio de pesagem do material verde no campo e secagem em estufa ventilada a $55^{\circ} \mathrm{C}$ durante 72 horas com nova pesagem. O nitrogênio total da forragem foi determinado pelo método de Kjeldhal, e os teores de FDN e LAS, segundo metodologia desenvolvida por Van Soest (1965), conforme descrito por Silva (1990).

O delineamento experimental utilizado foi de blocos casualizados com três repetições e seis tratamentos, constituídos por cinco genótipos de capim-elefante anão e pela cultivar Mott. Os dados foram submetidos à análise de variância e as médias dos genótipos foram comparadas pelo teste de Tukey a 5\% de significância. Foi utilizada a análise de regressão para avaliar o efeito dos intervalos de corte e para o desdobramento da interação genótipo x intervalo de corte.

\section{RESULTADOSEDISCUSSÃO}

O genótipo CNPGL 00-1-3 apresentou a maior altura de dossel, diâmetro de colmo e menor perfilhamento, sendo considerado de porte intermediário devendo ser utilizado em condições de capineira e não de pastejo. O genótipo CNPGL 94-34-3 e a cv. Mott apresentaram elevado número de perfilhos e relação folha-colmo. Os demais genótipos apesar de não se destacarem em função de determinado parâmetro morfológico, apresentaram um conjunto de características morfológicas de interesse para sua utilização em pastejo (tabela II).

Em relação à produtividade, houve interação de genótipos e intervalos de corte (tabela III). O genótipo CNPGL 00-1-3 apresentou maior TAMS em relação aos demais genótipos a partir de 56 dias, o que pode ser explicado pelo seu maior porte, conferindo-lhe maior proporção de colmo nas idades mais avançadas (tabela II). Entretanto, entre os demais genótipos de porte baixo, aqueles que se destacaram de maneira geral em relação à TAMS foram os

Tabela II. Altura do dossel (AD), índice de área foliar (IAF), diâmetro do colmo (DC), número de perfilhos (NP), relação folha-colmo $(F / C)$ e número de folhas expandidas $(N F)$ de genótipos de capim-elefante anão aos 84 dias de intervalo de corte. (Sward height (AD), leaf area index (IAF), stem diameter (DC), number of tiller (NP), leaf-stem ratio (F/C) and number of expanded leaves of dwarf elephangrass genotypes to 84 days of cutting).

\begin{tabular}{lcccccc}
\hline Genótipos & AD $(\mathrm{cm})$ & IAF & DC $(\mathrm{cm})$ & NP & F/C & NF \\
\hline Mott & $115,83^{\mathrm{c}}$ & $4,03^{\mathrm{b}}$ & $1,46^{\mathrm{b}}$ & $115,3^{\mathrm{a}}$ & $3,2^{\mathrm{a}}$ & $7,3^{\mathrm{a}}$ \\
$00-1-3$ & $206,17^{\mathrm{a}}$ & $8,02^{\mathrm{ab}}$ & $1,90^{\mathrm{a}}$ & $65,3^{\mathrm{b}}$ & $1,0^{\mathrm{bc}}$ & $6,3^{\mathrm{b}}$ \\
$94-34-3$ & $110,33^{\mathrm{c}}$ & $7,73^{\mathrm{ab}}$ & $1,56^{\mathrm{b}}$ & $126,6^{\mathrm{a}}$ & $3,6^{\mathrm{a}}$ & $9,0^{\mathrm{a}}$ \\
$92-198-7$ & $168,50^{\mathrm{b}}$ & $8,93^{\mathrm{ab}}$ & $1,33^{\mathrm{b}}$ & $67,3^{\mathrm{b}}$ & $1,4^{\mathrm{b}}$ & $6,3^{\mathrm{b}}$ \\
$92-117-3$ & $102,17^{\mathrm{c}}$ & $6,79^{\mathrm{b}}$ & $1,40^{\mathrm{b}}$ & $116,7^{\mathrm{a}}$ & $1,4^{\mathrm{b}}$ & $8,3^{\mathrm{a}}$ \\
$00-1-5$ & $96,33^{\mathrm{c}}$ & $5,38^{\mathrm{b}}$ & $1,43^{\mathrm{b}}$ & $98,0^{\mathrm{b}}$ & $1,6^{\mathrm{b}}$ & $6,4^{\mathrm{b}}$ \\
CV (\%) & 7,6 & 23,0 & 9,3 & 15,8 & 26,2 & 9,2 \\
\hline
\end{tabular}

Médias seguidas de mesma letra na coluna, não diferem entre si pelo teste de Tukey, $p \leq 0,05$.

Archivos de zootecnia vol. 60, núm. 229, p. 86. 
INTERVALOS DE CORTE E PRODUÇÃO E COMPOSIÇÃO DE CAPIM-ELEFANTE ANÃO

Tabela III. Taxa de acúmulo de matéria seca (kg.ha.dia $\left.{ }^{-1}\right)$ de genótipos de capim-elefante anão submetidos a intervalos de corte. (Accumulation rate of dry matter (kg.ha.dia ${ }^{-1}$ ) of dwarf elephangrass genotypes submitted cutting intervals).

\begin{tabular}{|c|c|c|c|c|c|c|c|c|}
\hline \multirow[t]{2}{*}{ Genótipos } & \multicolumn{6}{|c|}{ Intervalos de corte } & \multirow[t]{2}{*}{ Equação de regressão } & \multirow[t]{2}{*}{$\mathrm{R}^{2}$} \\
\hline & 14 & 28 & 42 & 56 & 70 & 84 & & \\
\hline Mott & 60,5 & 80,0 & 112,8 & 94,9 & 96,7 & 112,3 & $y=-0,64 x^{2}+13,13 x+39,86$ & 0,73 \\
\hline $00-1-3$ & 71,4 & 93,1 & 105,6 & 165,6 & 170,0 & 222,8 & $y=14,97 x+33,29$ & 0,95 \\
\hline $94-34-3$ & 75,6 & 77,1 & 85,0 & 82,9 & 88,7 & 95,5 & $y=1,89 x+70,95$ & 0,91 \\
\hline $92-198-7$ & 74,5 & 84,5 & 94,5 & 88,7 & 119,2 & 169,6 & $y=1,26 x^{2}-9,54 x+95,11$ & 0,93 \\
\hline $92-117-3$ & 51,6 & 64,9 & 89,4 & 82,0 & 103,5 & 96,1 & $y=4,73 x+48,15$ & 0,81 \\
\hline $00-1-5$ & 61,8 & 61,2 & 78,1 & 74,1 & 80,5 & 93,9 & $y=3,06 x+53,48$ & 0,86 \\
\hline
\end{tabular}

genótipos CNPGL 92-198-7, Mott, CNPGL 94-34-3 e CNPGL 92-117-3, respectivamente. O genótipo CNPGL 00-1-5 apresentou menor TAMS para quase todas as interações avaliadas. A cv. Mott e o genótipo CNPGL 92-198-7 apresentaram valores de TAMS que melhor se ajustaram ao modelo quadrático de regressão, enquanto que os demais genótipos se ajustaram ao modelo linear (tabela III).

Almeida et al. (2000) trabalhando com a $\mathrm{cv}$. Mott em diferentes ofertas de forragem obtiveram taxa de acúmulo de matéria seca que variaram de 52,9 a 70,4 kg.ha.dia ${ }^{-1}$, utilizando o período de descanso de 28 dias. Considerando-se que as perdas decorrentes da ação do animal na pastagem são de 20$30 \%$, pode-se concluir que os dados destes autores foram semelhantes aos do presente experimento.

Santos et al. (2004) avaliando Panicum maximum cv. Mombaça em sistema de pastejo entre outubro de 1995 e abril de 1996, verificaram taxas de acúmulo de matéria seca aos 28 dias de descanso entre 130 e 190 kg.ha.dia-1 . Entretanto, estes autores utilizaram doses de adubação nitrogenada superiores ao deste experimento (400 kg.ha' ${ }^{1}$.

Santos et al. (2003) avaliaram a produtividade dos capins Pioneiro, Mott, Mombaça, Tanzânia e Marandu em intervalos de corte de 35 dias e encontraram melhores resultados com a cv. Pioneiro, no entanto, as
TAMS encontradas de 210,$0 ; 150,8 ; 160,8$; 149,4 e 157,1 kg.ha.dia ${ }^{-1}$ respectivamente para as forrageiras supracitadas, são superiores às encontradas neste trabalho considerando o acúmulo de massa obtido entre 28 e 42 dias de intervalo de corte.

Deresz (2001) observou produção de matéria seca de capim-elefante de porte alto para os períodos de descanso de 30, 36 e 45 dias de 11460,12803 y $14190 \mathrm{~kg} / \mathrm{ha}$, respectivamente. Estes valores são semelhantes aos observados neste experimento independente do genótipo e do intervalo de corte. A provável explicação é devido à ação do pisoteio dos animais sob a pastagem, o que não aconteceu no presente experimento. Outra explicação, diz respeito a maior adaptação de genótipos de porte baixo à desfolhação, quando comparados com forrageiras de porte alto, que são mais prejudicadas pela eliminação do meristema apical.

É importante salientar que os dados observados neste experimento foram semelhantes aos obtidos por diversos autores com a cv. Mott, como os de Veiga (1983), Souza Filho (1987) e Thiago et al. (1992), evidenciando a adaptabilidade e o elevado potencial produtivo destes genótipos para a região Norte Fluminense.

O teor de proteína bruta também mostrou interação significativa dos genótipos com os intervalos de corte (tabela IV). Os genótipos CNPGL 00-1-3 e CNPGL 00-1-5 
apresentaram comportamento linear. Entretanto, o genótipo CNPGL 00-1-5 possui características morfológicas (tabela II) que não condizem com este comportamento linear. Provavelmente este comportamento foi devido ao ataque de pragas e doenças, que podem ter aumentado a proporção de material senescente influenciando na sua qualidade.

Os demais genótipos apresentaram comportamento quadrático, ou seja, houve uma queda acentuada entre 14 e 42 dias e a partir desta idade ocorreu menor redução do teor protéico. Para todos os genótipos avaliados o teor protéico apresentou grande queda com o aumento da maturidade das plantas, entretanto, os menores valores observados foram superiores a $7 \%$, valor considerado mínimo para a manutenção de condições ideais do ambiente ruminal.

Os teores de PB observados foram superiores aos encontrados por Deresz (2001), o qual trabalhou com períodos de descanso de 30,36 e 45 dias em sistema de pastejo. $O$ efeito do intervalo de corte sobre o teor protéico de capim-elefante anão também foi observado por Veiga (1990).

Mari (2003) estudando o efeito do intervalo de corte em Braquiária brizantha cv. Marandu verificou valores protéicos médios de 13,$3 ; 12,0 ; 10,7 ; 9,0 ; 9,9$ e $8,9 \%$ na MS para os intervalos de corte de $15,30,45,60,75$ e 90 dias. Pode-se observar que o teor protéico no primeiro intervalo de corte é inferior ao observado neste trabalho. Este fato ocorreu porque a Braquiária brizantha cv. Marandu, apesar de ser uma excelente forrageira, não possui a mesma eficiência de extração e conversão dos nutrientes do solo que o capim-elefante. Os valores observados por esta autora foram semelhantes aos obtidos neste trabalho a partir de 28 dias.

Santos et al. (2003) encontraram valores de 10,$2 ; 8,5 ; 6,9 ; 7,3$ e $7,2 \%$ de PB para os capins Pioneiro, Mott, Mombaça, Tanzânia e Marandu aos 35 dias de período de descanso. Estes resultados são inferiores aos deste trabalho, e uma possível explicação pode ser devida à menor quantidade de adubo nitrogenado aplicados em cobertura $\left(60 \mathrm{~kg} \cdot \mathrm{ha}^{-1}\right)$.

Os dados referentes ao teor de FDN dos genótipos de capim-elefante anão em função dos intervalos de corte e suas respectivas equações de regressão são apresentados na tabela V. Pode-se observar que o teor de FDN na matéria seca apresentou variação significativa em função dos intervalos de corte apenas para os genótipos CNPGL 001-3 e CNPGL 92-198-7. Esse resultado é comum, devido ao acréscimo nos constituintes da parede celular com aumento da participação do colmo na constituição de plantas de maior altura de dossel. Para o genótipo CNPGL 94-34-3 e a cv. Mott, o avanço da maturidade da planta não influenciou no teor de FDN devido provavelmente à elevada relação $\mathrm{F} / \mathrm{C}$ destes

Tabela IV. Proteína bruta (\%MS) de genótipos de capim-elefante anão submetidos a diferentes intervalos de corte. (Crude protein (\%MS) of dwarf elephangrass genotypes submitted cutting intervals).

\begin{tabular}{|c|c|c|c|c|c|c|c|c|}
\hline \multirow[t]{2}{*}{ Genótipos } & \multicolumn{6}{|c|}{ Intervalos de corte } & \multirow[t]{2}{*}{ Equação de regressão } & \multirow[t]{2}{*}{$\mathrm{R}^{2}$} \\
\hline & 14 & 28 & 42 & 56 & 70 & 84 & & \\
\hline Mott & 17,95 & 14,45 & 11,66 & 11,99 & 10,60 & 9,72 & $y=0,0017 x^{2}-0,273 x+21,08$ & 0,95 \\
\hline $00-1-3$ & 17,54 & 14,83 & 11,52 & 10,39 & 8,41 & 7,11 & $y=-1,0358 x+18,88$ & 0,96 \\
\hline $94-34-3$ & 18,23 & 14,15 & 11,59 & 11,68 & 11,05 & 11,22 & $y=0,129 x^{2}-2,441 x+22,24$ & 0,96 \\
\hline $92-198-7$ & 18,75 & 15,90 & 11,31 & 12,11 & 8,58 & 8,11 & $y=0,0015 x^{2}-0,296 x+22,58$ & 0,94 \\
\hline $92-117-3$ & 19,01 & 15,53 & 13,52 & 11,94 & 10,33 & 9,62 & $y=0,0014 x^{2}-0,268 x+22,31$ & 0,99 \\
\hline $00-1-5$ & 17,43 & 14,79 & 13,60 & 11,51 & 11,31 & 10,34 & $y=-0,6858 x+17,96$ & 0,93 \\
\hline
\end{tabular}

Archivos de zootecnia vol. 60, núm. 229, p. 88. 
Tabela $\boldsymbol{V}$. Fibra em detergente neutro $(\% M S)$ de genótipos de capim-elefante anão submetidos a intervalos de corte. (Neutral fiber detergent (\%MS) of dwarf elephantgrass genotypes submitted cutting intervals).

\begin{tabular}{lcccccllc}
\hline Genótipos & \multicolumn{9}{c}{ Intervalos de corte } & Equação de regressão & $R^{2}$ \\
& 14 & 28 & 42 & 56 & 70 & 84 & & \\
\hline Mott & 63,88 & 65,47 & 63,13 & 68,82 & 70,15 & 71,48 & ns & - \\
$00-1-3$ & 63,49 & 65,89 & 70,14 & 72,90 & 74,40 & 75,23 & y=1,2428 x+61,6450 & 0,95 \\
$94-34-3$ & 60,76 & 64,44 & 66,20 & 62,99 & 67,27 & 68,08 & ns & - \\
$92-198-7$ & 61,58 & 61,67 & 67,54 & 69,44 & 73,36 & 73,49 & y=1,3787x+58,1993 & 0,93 \\
$92-117-3$ & 61,41 & 63,70 & 67,11 & 66,01 & 70,73 & 68,80 & ns & - \\
$00-1-5$ & 62,43 & 62,90 & 66,21 & 68,59 & 67,14 & 67,94 & ns & - \\
\hline
\end{tabular}

ns= interação não significativa.

genótipos mesmo nas idades mais avançadas (tabela II). Os genótipos CNPGL 92117-3 e CNPGL 00-1-5 provavelmente apresentaram pouca variação da relação $\mathrm{F} / \mathrm{C}$ com o avanço da maturidade da planta, influenciando o comportamento do teor de FDN. Entretanto, apesar de não ter ocorrido interação significativa, observa-se evidente diferença quanto ao teor de FDN entre o menor e o maior intervalo de corte para estes genótipos.

Os valores médios para os genótipos sem levar em consideração os intervalos de corte foram de 70,$3 ; 67,8 ; 67,1 ; 66,3 ; 65,8 \mathrm{e}$ $64,9 \%$ de FDN para os genótipos CNPGL 001-3, CNPGL 92-198-7, Mott, CNPGL 92-1173, CNPGL 00-1-5 e CNPGL 94-34-3.

Teores de FDN aproximados foram constatados por Flores et al. (1993), Almeida et al. (1996), Santos et al. (2003) e por Mari (2003) que também verificaram maiores teores de FDN com o aumento da idade de corte. A FDN correlaciona-se mais estreitamente com o consumo voluntário dos animais, sendo que valores acima de 55 a $60 \%$ correlacionamse de maneira negativa (Van Soest, 1965). Os valores de FDN encontrados estiveram sempre acima do valor crítico de $55 \%$ e, portanto, o consumo voluntário das forrageiras em pastejo poderia ser limitado no caso de uma pressão de pastejo alta, que reduziria a seletividade dos bovinos.

Costa et al. (2007) estudando o compor- tamento da B. Brizantha cv. MG-5 em função dos intervalos de corte, observaram variação nos teores de FDN superiores aos deste trabalho. Os valores obtidos foram de 57,4; 60,$0 ; 65,5$ e $70,8 \%$ FDN para os intervalos de corte de 15, 20, 30 e 60 dias.

Houve interação de genótipos e intervalos de corte para os valores de LAS somente para os genótipos CNPGL 00-1-3, CNPGL 92-198-7 e CNPGL 92-117-3 (tabela VI). Estes genótipos apresentaram comportamento linear em função do avanço da maturidade da planta. Os valores médios gerais observados foram de 6,$6 ; 7,5 ; 7,3 ; 7,2 ; 7,6$ e 7,3\% de LAS para os genótipos Mott, CNPGL 001-3,CNPGL94-34-3,CNPGL92-198-7,CNPGL 92-117-3 e CNPGL 00-1-5, respectivamente.

Da mesma forma que observado para a FDN, naqueles genótipos que não apresentaram interação significativa pode-se observar aumento da LAS entre os menores e os maiores intervalos de corte.

Flores et al. (1993) trabalhando com a cv. Mott aos 35 dias de intervalo de corte, observaram teores médios de 5,6\% para lignina. Santos et al. (2001) não observaram diferença significativa para o capim-elefante roxo em diferentes alturas de corte, obtendo média de $8,5 \%$ de lignina, muito superior ao observado neste estudo.

Balsalobre et al. (2001) relataram que as maiores mudanças que ocorrem na compo- 
ARAÚJO, VASQUEZ, SILVA, LIMA, LISTA, DEMINICISE CAMPOS

Tabela VI. Lignina em ácido sulfúrico (\%MS) de genótipos de capim-elefante anão submetidos a intervalos de corte. (Sulfuric acid lignin (\%MS) of dwarf elephangrass genotypes submitted cutting intervals).

\begin{tabular}{|c|c|c|c|c|c|c|c|c|}
\hline \multirow[t]{2}{*}{ Genótipos } & \multicolumn{6}{|c|}{ Intervalos de corte } & \multirow{2}{*}{ Equação de regressão } & \multirow[t]{2}{*}{$\mathrm{R}^{2}$} \\
\hline & 14 & 28 & 42 & 56 & 70 & 84 & & \\
\hline Mott & 2,5 & 3,3 & 5,2 & 5,4 & 5,1 & 6,2 & $\mathrm{~ns}$ & - \\
\hline $00-1-3$ & 3,2 & 4,5 & 4,6 & 4,8 & 7,8 & 7,9 & $y=0,068 x+2,10$ & 0,86 \\
\hline $94-34-3$ & 3,7 & 4,8 & 4,5 & 5,7 & 5,8 & 5,7 & ns & - \\
\hline $92-198-7$ & 3,8 & 4,2 & 5,1 & 5,4 & 5,6 & 7,1 & $y=0,042 x+3,10$ & 0,93 \\
\hline $92-117-3$ & 4,1 & 4,7 & 4,7 & 5,0 & 7,4 & 7,4 & $y=0,050 x+3,06$ & 0,83 \\
\hline $00-1-5$ & 3,9 & 4,5 & 4,8 & 4,7 & 6,5 & 6,4 & ns & - \\
\hline
\end{tabular}

ns= interação não significativa.

sição das plantas forrageiras são aquelas decorrentes de sua maturidade. A maioria das espécies forrageiras sofre declínio no seu valor nutritivo com o aumento da idade, resultando da menor relação folha/haste combinada com a crescente lignificação da parede celular. Isto foi observado neste estudo, tanto em relação à maturidade da planta (todos os genótipos), quanto devido à relação folha/colmo (principalmente nos genótipos CNPGL 00-1-3, CNPGL 92-198-7e CNPGL 92-117-3).

\section{CONCLUSÕES}

Com base nos dados de TAMS e com-

\section{BIBLIOGRAFIA}

Almeida, E.X., Maraschin, G.E., Harthmann, O.E.L., Ribeiro Filho, H.M.N. e Setelich, E.A. 2000. Oferta de forragem de capim-elefante anão 'mott' e o rendimento animal. Rev. Bras. Zootecn., 29: 1288-1295.

Almeida, E.X., Maraschin, G.E. e Stuker, H. 1996. Oferta de forragem de capim-elefante anão $(P$. purpureum Schum.) cv. Mott. composição química e digestibilidade. Em: Reunião Anual da Sociedade Brasileira de Zootecnia, 33. Fortaleza. Anais.. SBZ. Fortaleza. pp. 93-94.

Balsalobre, M.A.A., Nussio, L.G. e Martha Júnior, G.B. 2001. Controle de perdas na produção de silagem de gramíneas tropicais. Em: Simpósio sobre manejo da pastagem, 2001, Piracicaba. posição bromatológica, os genótipos CNPGL 92-198-7, CNPGL 94-34-3 e a cv. Mott foram considerados os mais promissores, sendo selecionados para a fase de avaliação em sistema de pastejo. Os genótipos CNPGL 00-1-3, CNPGL 92-198-7 e CNPGL 94-34-3 apresentaram de maneira geral rendimento de matéria seca e teor de proteína bruta superiores a cv. Mott, evidenciando a eficácia dos trabalhos de melhoramento genético do capim-elefante anão. Os genótipos CNPGL 92-198-7 e CNPGL 94-34-3 são forrageiras promissoras devendo ser recomendados para a avaliação sob condições de pastejo.

Anais.. FEALQ. Piracicaba. pp. 890-911.

Cândido, M.J.D., Alexandrino, E. e Gomide, J.A. 2005. Duração do período de descanso e crescimento do dossel de Panicum maximum cv. Mombaça sob lotação intermitente. Rev. Bras. Zootecn., 34: 398-405.

Costa, K.A.P., Oliveira, I.P., Faquin, V., Neves, B.P., Rodrigues, C. e Sampaio, F.M.T. 2007. Intervalo de corte na produção de massa seca e composição químico-bromatológica da Brachiaria brizantha cv. MG-5. Ciênc. Agrotec., 31: 1197-1202.

Deresz, F. 2001. Influência do período de descanso da pastagem de capim-elefante na produção de leite de vacas mestiças holandês $\mathrm{x}$ zebu.

Archivos de zootecnia vol. 60, núm. 229, p. 90. 
INTERVALOS DE CORTE E PRODUÇÃO E COMPOSIÇÃO DE CAPIM-ELEFANTE ANÃO

Rev. Bras. Zootecn., 30: 461-469.

EMBRAPA. 2006. Sistema brasileiro de classificação de solos. $2^{\mathrm{a}}$ ed. Empresa Brasileira de Pesquisa Agropecuária Solos. Rio de Janeiro. $306 \mathrm{pp}$.

Flores, J.A., Moore, J.E. and Sollenbergert, L.E. 1993. Determinants of forage quality in pensacola bahiagrass and Mott elephantgrass. J. Anim. Sci., 71: 1606-1614.

Köppen, W. 1948. Climatologia: con un estudio de los climas de la tierra. Fondo de Cultura Econômica. México. 479 pp.

Lopes, F.C.F., Deresz, F., Rodriguez, N.M., Aroeira, L.J.M., Borges, I., Matos, L.L. e Vittori, A. 2003. Disponibilidade e perdas de matéria seca em pastagem de capim-elefante (Pennisetum purpureum, Schumack) submetida a diferentes períodos de descanso. Arq. Bras. Med. Vet. Zoo., 55: 454-460.

Mari, L.J. 2003. Intervalo entre cortes em capim marandu (Braquiária brizantha Staf cv. Marandu): produção, valor nutritivo e perdas associadas à fermentação da silagem. Dissertação (Mestrado em Agronomia). Escola Superior de Agricultura Luiz de Queiroz. Piracicaba. $159 \mathrm{pp}$

Mott, G.O. 1984. Carrying capacity and live weight gains from dwarf elephant-grass. In: Florida Beef Cattle Short Course Practice. Anais... Gainesville. 111 pp.

Santana, J.R., Pereira, J.M. e Ruiz, M.A.M. 1994. Avaliação de cultivares de capim-elefante (Pennisetum purpureum Schum.), no sudoeste da Bahia. Il - Agrossistema de Itapetinga. Rev. Soc. Bras. Zootecn., 23: 507-517.

Santos, E.A., Silva, D.S. e Queiroz Filho, J.L. 2001. Composição química do capim-elefante cv. roxo cortado em diferentes alturas. Rev. Bras. Zootecn., 30: 18-23.
Santos, M.V.F., Dubeux Júnior, J.C.B., Silva, M.C. Santos, S.F., Ferreira, R.L.C., Mello, A.C.L., Farias, I. e Freitas, E.V. 2003. Produtividade e composição química de gramíneas tropicais na zona da Mata de Pernambuco. Rev. Bras. Zootecn., 32: 821-827.

Santos, P.M., Balsalobre, M.A.A. e Corsi, M. 2004. Características morfogenéticas e taxa de acúmulo de forragem do capim-mombaça submetido a três intervalos de pastejo. Rev. Bras. Zootecn., 33: 843-851.

Silva, D.J. 1990. Análise de alimentos (métodos químicos e biológicos). $2^{\mathrm{a}}$ ed. UFV. Viçosa. 165 pp.

Souza Filho, A.P.S. 1987. Rendimento forrageiro, composição química e digestibilidade das frações folha e colmo do capim-elefante (Pennisetum purpureum Schum.) dwarf em diferentes idades. Lavras. Dissertação (Mestrado em Zootecnia). Escola Superior de Agricultura de Lavras. Lavras. 104 pp.

Thiago, L.R.L.S., Macedo, M.C.M., Nicodemo, M.L.F. e Anjos, C.R. 1992. Avaliação de cultivares e híbridos de Pennisetum purpureum em Mato Grosso do Sul. Em: Reunião Anual da Sociedade Brasileira de Zootecnia, 29. 1992. Anais.. SBZ. Lavras. pp. 78.

Van Soest, P.J. 1965. Voluntary intake relation to chemical composition and digestibility. J. Anim. Sci., 24: 834-844.

Veiga, J.B. 1983. Effect of grazing management upon a dwarf elephantgrass (Pennisetum purpureum Schum.) pasture. Thesis (Doctor of Phylosophy). University of Florida. Gainesville. $197 \mathrm{pp}$.

Veiga, J.B. 1990. Utilização do capim-elefante sob pastejo. Em: Simpósio Sobre Capim-Elefante, 1. Coronel Pacheco. Anais.. EMBRAPA-Gado de Leite. Coronel Pacheco. pp. 133. 